\title{
The right weight: body fat, menarche and fertility
}

\author{
BY ROSE E. FRISCH \\ Harvard Center for Population and Development Studies, 9 Bow Street, Cambridge, \\ MA 02138, USA
}

Women who are underweight, or too lean, because of injudicious dieting or excessive athletic activity, or both, experience disruption of their reproductive ability (Frisch \& McArthur, 1974; Frisch et al. 1980b, 1981b; Green et al. 1988). It is now well documented that moderate weight loss, in the range of $10-15 \%$ of normal weight-for-height, unassociated with anorexia nervosa (where weight loss is in the range of $30 \%$ below ideal weight) results in amenorrhoea. The amenorrhoea is due to hypothalamic dysfunction (Vigersky et al. 1977; Nillius, 1983). Weight loss in this moderate range is equivalent to a loss of one-third of body fat (Frisch \& McArthur, 1974). If the excessive leanness occurs before menarche, menarche may be delayed until as late as age 19 or 20 years (Frisch et al. $1980 \mathrm{~b}, 1981 \mathrm{~b}$ ). Under special medical circumstances, a normal menarche and ovulatory cycles can be delayed until after 30 years of age (Feigelman et al. 1987).

In addition to these disruptive effects of weight loss and athletic activity on the menstrual cycle, women who exercise moderately or who are regaining weight into the normal range may have a menstrual cycle which appears to be normal, but which actually has a shortened luteal phase or is anovulatory (Cumming et al. 1985; Prior, 1985). All these partial or total disruptions of reproductive ability are usually reversible after varying periods of time following weight gain or decreased athletic training, or both (McArthur et al. 1976; Frisch et al. 1981b).

Excessive fatness is also associated with infertility in women (Hartz et al. 1979; Pasquali et al. 1989), as was observed for animals almost one century ago by Marshall \& Peel (1908). Loss of weight restores fertility of the women and of the animals.

Thus, both too little and too much fat are associated with infertility. These associations may be causal, and the high percentage of body fat, $26-28 \%$ in women after completion of growth, may be necessary for, and may influence, reproduction directly (Frisch, 1974, 1984, 1985, 1988). This hypothesis leads to the prediction of minimum or threshold weights-for-height for the onset and maintenance of regular ovulatory menstrual cycles (Frisch \& McArthur, 1974). These weights have been found to be useful clinically as target weights for the restoration of ovulatory cycles in cases of amenorrhoea due to weight loss (Nillius, 1983; Speroff et al. 1983). I consider that both the absolute and relative amounts of fat are important, since the lean mass and the fat must be in a particular absolute range, as well as relative range, i.e. the female must be big enough to reproduce successfully (Frisch, 1977).

The association of reproductive dysfunction with changes in body composition has been controversial because most estimations of body composition are indirect. Using magnetic resonance imaging (MRI) we measured subcutaneous and internal fat, overall and at six sites, in athletes and compared the results with those of controls. We also analysed the MRI data in relation to ovulatory status of these subjects and in relation to the extent of 2-hydroxylation of oestradiol to a non-potent metabolite (Gerard et al. 1991; Frisch et al. 1992, 1993), as will be reported later (p. 124). 


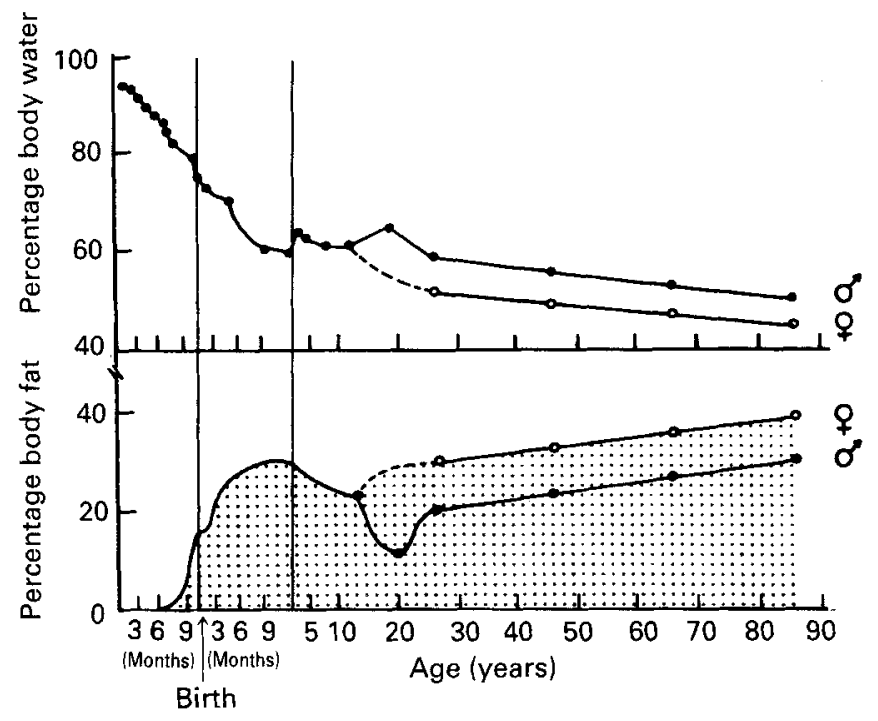

Fig. 1. Changes in body water as a percentage of body weight throughout the lifespan, and corresponding changes in the percentage of body fat. (Adapted from Friis-Hansen, 1965; reprinted with permission from the Pergamon Press).

\section{WHY FAT?: ENERGY COST OF REPRODUCTION AND FEMALE BODY COMPOSITION}

A human pregnancy and lactation each have a high energy cost: a pregnancy requires about $210 \mathrm{~kJ}$ in addition to normal metabolic requirements (Emerson et al. 1972). Lactation requires about $4 \mathrm{~kJ} / \mathrm{d}$ (FAO, 1957). In premodern times lactation was an essential part of reproduction.

While the reproductive system is slowly maturing during growth, the body changes in composition as well as in size and proportions. Direct measurements of body water of girls from birth to completion of growth at ages 16-18 years show a continuous decline in the proportion of body water, because girls have a large relative increase in body fat (Friis-Hansen, 1965; Fig. 1). The decrease in body water is particularly rapid during the adolescent growth spurt in height and weight, which precedes menarche (Frisch, 1974).

The body of a well-nourished woman at the completion of growth contains about $26-28 \%$ fat and about $52 \%$ water, whereas the body of a man at completion of growth contains about $14 \%$ fat and $61 \%$ water (Edelman et al. 1952; Moore et al. 1963). A young girl and boy of the same height and weight, as shown in Table 1, differ markedly in body water and fat contents (Frisch, 1981). The main function of the $16 \mathrm{~kg}$ of stored female fat, which is equivalent to $600 \mathrm{~kJ}$, may be to provide energy for a pregnancy and for about 3 months lactation. In prehistoric times when the food supply was scarce, or fluctuated seasonally, stored fat would have been necessary for successful reproduction. Fat is a very labile component of body weight; therefore, body fat would reflect changes in food supplies more rapidly than other tissues (Frisch, 1984). 
Table 1. Comparison of body composition of a girl aged 18 years and a boy aged 15 years of the same height and weight (From Frisch, 1981)

\begin{tabular}{lcc}
\hline \hline & Girl & Boy \\
\hline Height $(\mathrm{m})$ & $1 \cdot 65$ & $1 \cdot 65$ \\
Wt $(\mathrm{kg})$ & $57 \cdot 0$ & $57 \cdot 0$ \\
Total body water $(\mathrm{TW} ; \mathrm{l})$ & $29 \cdot 5$ & $36 \cdot 0$ \\
Lean body wt (TW/0.72; kg) & 41.0 & $50 \cdot 0$ \\
Fat (kg) & $16 \cdot 0$ & $7 \cdot 0$ \\
Fat $/$ body wt (BWt) $(\%)^{*}$ & $28 \cdot 0$ & $12 \cdot 0$ \\
TW/BWt \% & 51.8 & 63.0 \\
\hline
\end{tabular}

* $100-(($ TW/BWt \% $) / 0 \cdot 72)$.

BODY WEIGHT AND INFANT SURVIVAL

Infant survival is correlated with birth weight, and birth weight is correlated with the prepregnancy weight of the mother and, independently, her weight gain during pregnancy (Eastman \& Jackson, 1968). From a teleological and evolutionary view, it is possible that the physical ability to deliver a viable infant and the hypothalamic control of reproduction are synchronized; adipose tissue may be the synchronizer.

\section{HOW ADIPOSE TISSUE MAY REGULATE FEMALE REPRODUCTION}

There are at least four known mechanisms by which adipose tissue may directly affect ovulation and the menstrual cycle and, hence, fertility.

1. Adipose tissue is a significant extragonadal source of oestrogen (Siiteri \& McDonald, 1973; Siiteri, 1981). Conversion of androgen to oestrogen takes place in adipose tissue of the breast and abdomen (Nimrod \& Ryan, 1975), the omentum (Perel \& Killinger, 1979), and the fatty marrow of the long bones (Frisch et al. 1975). This conversion accounts for roughly one-third of the circulating oestrogen of premenopausal women. It is the main source of oestrogen in postmenopausal women. Men also convert androgen into oestrogen in body fat (Siiteri \& MacDonald, 1973).

2. Body weight, hence fatness, influences the direction of oestrogen metabolism to more potent or less potent forms (Fishman et al. 1975). Compared with normal women very thin women have high levels of the 2-hydroxylated form of oestrogen, which is relatively inactive and has little affinity for the oestrogen receptor. Lean women athletes also have elevated levels of the 2-hydroxylated form of oestrogen (Snow et al. 1989; Frisch et al. 1993). In contrast, obese women metabolize less oestrogen to the 2-hydroxylated form and have a relatively higher level of the 16-hydroxylated form, which has potent oestrogenic activity (Schneider et al. 1983).

3. Obese women (Siiteri, 1981) and young girls who are relatively fatter (Apter et al. 1984) have diminished capacity for oestrogen to bind to serum sex-hormone-binding globulin (SHBG); this results in an elevated percentage of free serum oestradiol. Since SHBG regulates the availability of oestradiol to the brain and other target tissues, the changes in the proportion of body fat relative to lean mass may influence reproductive performance through the intermediate effects of SHBG. 
4. Adipose tissue of obese women stores steroid hormones (Kaku, 1969).

Changes in relative fatness might also affect reproductive ability indirectly by disturbing the hypothalamic regulation of body temperature and energy balance. Very lean women, both anorexic and non-anorexic, display abnormalities of temperature regulation, in addition to delayed response, or lack of response, to exogenous luteinizing hormone-releasing hormone (Vigersky et al. 1977).

\section{HYPOTHALAMIC DYSFUNCTION, GONADOTROPHIN SECRETION AND WEIGHT LOSS}

The amenorrhoea of underweight and excessively lean women is due to hypothalamic dysfunction (Vigersky et al. 1977; Nillius 1983). Hypothalamic dysfunction has been implicated also in the amenorrhoea of athletes (Cumming et al. 1985). Consistent with the view that this type of amenorrhoea is adaptive, the pituitary-ovarian axis is apparently intact, and functions when exogenous gonadotrophin-releasing hormone (GnRH) is given in pulsed doses (Nillius, 1983) or in a bolus (Vigersky et al. 1977). Women with this type of hypothalamic amenorrhoea have both quantitative and qualitative changes in the secretion of the gonadotrophins, luteinizing hormone (LH), follicle-stimulating hormone (FSH), and oestrogen: (1) LH, FSH, and oestradiol levels are low, (2) the secretion of $\mathrm{LH}$ and the response to GnRH are reduced in direct correlation with the amount of weight loss (Warren et al. 1975; Vigersky et al. 1977), (3) the maturity of the $24 \mathrm{~h} \mathrm{LH}$ secretory pattern and body weight are related; weight loss results in an age-inappropriate secretory pattern resembling that of prepubertal or early pubertal children. Weight gain restores the postmenarcheal secretory pattern (Boyar et al. 1974).

Supportive also of the view that this type of hypothalamic amenorrhoea is adaptive are the findings of Van der Spuy et al. (1988) that women in whom ovulation had been induced had a higher risk of low-birth-weight babies who were small for dates, and this risk was greatest $(54 \%)$ in those who were underweight. These authors conclude that the most suitable treatment for infertility secondary to weight-related amenorrhoea is dietary, rather than induction of ovulation.

\section{THE PHYSIOLOGICAL BASIS OF REPRODUCTIVE ABILITY}

\section{Weight at menarche}

The idea that relative fatness is important for female reproductive ability followed from the findings that the events of the adolescent growth spurt, particularly menarche, were closely related to an average critical body weight (Frisch \& Revelle, 1971). This result was unexpected for human beings, although it was well known for monkeys (Van Wagenen, 1949) and rats (Kennedy \& Mitra, 1963) that puberty is more closely related to body weight than to chronological age.

For United States girls at menarche mean weight was 47.8 (SE 0.5 ) $\mathrm{kg}$, mean height 1.59 (SE 0.005) $\mathrm{m}$ and mean age 12.9 (SE 0.1) years. This mean age included girls from Denver. who had a slightly later age of menarche than the sea-level populations, due to the slowing effect of altitude on prenatal and postnatal weight growth (Frisch \& Revelle, 1971). 


\section{The secular trend toward an earlier age of menarche}

The idea that menarche is associated with a critical weight for a population explained simply many observations associated with early or late menarche. Observations of earlier menarche are associated with attaining the critical weight more quickly. The most important example is the secular (long-term) trend towards an earlier menarche of about 3 or 4 months per decade in Europe in the last 100 years (Wyshak \& Frisch, 1982). Our explanation is that children now are bigger sooner; therefore, girls on average reach $46-47 \mathrm{~kg}$, the mean weight at menarche of United States and many European populations, more quickly. According to our hypothesis, the secular trend should end when the weight of children of successive cohorts remains the same because of the attainment of maximum nutrition and child care; this has happened in the United States (Frisch \& Revelle, 1971; Wyshak \& Frisch 1982).

Conversely, a late menarche is associated with body weight growth that is slower either prenatally or postnatally, or both, so that the average critical weight is reached at a later age. Malnutrition delays menarche (Tanner, 1962), twins have later menarche than do singletons of the same population, and high-altitude delays menarche (Frisch \& Revelle, 1971).

\section{Components of weight at menarche}

Individual girls have menarche at varied weights and heights (Frisch \& Revelle, 1971). In order to make the suggestion of a critical weight meaningful for an individual girl at menarche, we analysed the components of body weight at menarche (Frisch et al. 1973). We investigated body composition at menarche because total body water (TW) and lean body weight (TW/0.72) are more closely correlated with metabolic rate than is body weight. Metabolic rate was considered an important clue, since Kennedy (Kennedy \& Mitra, 1963; Kennedy, 1969) suggested a food intake-lipostat-metabolic signal to explain his elegant findings on weight and puberty in the rat.

The greatest change in estimated body composition of both early- and late-maturing girls during the adolescent growth spurt was a large increase in body fat, from about 5 to $11 \mathrm{~kg}$, a $120 \%$ increase, compared with a $44 \%$ increase in lean body weight. Thus, there was a change in the lean body weight:fat ratio from $5: 1$ at initiation of the spurt to $3: 1$ at menarche. The shortest, lightest girls at menarche have a smaller absolute amount of fat, 8.9 (SE 0.4 ) $\mathrm{kg}$, compared with that of the tallest, heaviest girls, 12.3 (SE 0.6 ) $\mathrm{kg}$ (the mean of all subjects is $11.5(\mathrm{SE} 0.3) \mathrm{kg}$ ). However, both extreme groups have about $22 \%$ of their body weight as fat at menarche as do all subjects, and the lean body weight:fat of both groups is in the range of 3:1, as it is in all subjects (Frisch et al. 1973).

Since adipose tissue can convert androgens to oestrogens (Siiteri \& MacDonald, 1973) the relative degree of fatness can be directly related to the quantity of circulating oestrogen. The biological effectiveness of the oestrogen is also related to body weight (Fishman et al. 1975) and relative fatness (Frisch et al. 1992, 1993). A rapid rate of adolescent growth results in more fat gain per unit lean body mass than a slower rate of growth. Thus, the degree of adiposity relates rate of growth, nutrition, and physical work, to the energy requirements for reproduction. 


\section{Fatness as a determinant of minimal weights for menstrual cycles}

As shown in Table 1 and Fig. 1, TW as a percentage of body weight (TW/BWt \%) is an index of fatness (Friis-Hansen, 1956). TW/BWt \% values for 181 girls followed from menarche to the completion of growth at 16-18 years of age provided a method of determining a minimal weight-for-height necessary for menarche in primary amenorrhoea and for the resumption of normal, ovulatory cycles in cases of secondary amenorrhoea, when the amenorrhoea is due to undernutrition, and/or intensive exercise (Frisch \& McArthur, 1974). These weights have been found useful in the evaluation and treatment of patients with primary or secondary amenorrhoea due to weight loss (Nillius, 1983).

Percentiles of TW/BWt \%, which equate to percentiles of fatness, were made at menarche and for the same 181 girls at 18 years of age, the age at which body composition was stabilized (Frisch, 1976). Patients with amenorrhoea due to weight loss, having excluded other possible causes, were studied in relation to weight indicated by the diagonal percentile lines of TW/BWt $\%$. We found that TW/BWt $\%$ of $56 \cdot 1$, the 10 th percentile at age 18 years, which is equivalent to about $22 \%$ body fat, indicated a minimal weight-for-height necessary for the restoration and maintenance of menstrual cycles. For example, a 20-year-old woman whose height is $1.65 \mathrm{~m}$ (65 in) should weigh at least $49 \mathrm{~kg}(108 \mathrm{lb})$ before menstrual cycles would be expected to resume (Fig. 2). The weights at which menstrual cycles ceased or resumed in postmenarcheal patients aged 16 years and older were about $10 \%$ heavier than the minimal weights for the same height observed at menarche (Frisch \& McArthur, 1974; Fig. 2).

Both early- and late-maturing girls gain an average of $4.5 \mathrm{~kg}$ fat from menarche to 18 years of age. Almost all this gain is achieved by 16 years of age, when mean body fat is 15.7 (SE 0.3 ) $\mathrm{kg}, 27 \%$ body weight. At 18 years of age mean body fat is 16.0 (SE 0.3 ) $\mathrm{kg}$, $28 \%$ body weight (mean body weight $57 \cdot 1$ (SE $0 \cdot 6) \mathrm{kg}$ ). Reflecting this increase in fatness, the TW/BWt \% decreases from 55.1 (SE 0.2) at menarche $(12.9$ (SE 0.1) years in our sample) to $52 \cdot 1($ SE $0 \cdot 2)$ at 18 years of age (Frisch, 1976).

Because girls are less fat at menarche than when they achieve stable reproductive ability, the minimal weight for onset of menstrual cycles in cases of primary amenorrhoea due to undernutrition or exercise is indicated by the 10 th percentile of TW/BWt $\%$ at menarche, $59 \cdot 8 \%$, which is equivalent to about $17 \%$ body fat. For example, a 15-year-old girl whose completed height is $1.65 \mathrm{~m}$ (65 in) should weigh at least $43.6 \mathrm{~kg}$ ( $96 \mathrm{lb}$ ) before menstrual cycles can be expected to begin (Fig. 2).

The minimum weights indicated in Fig. 2 would be used also for girls who become amenorrhoeic as a result of weight loss shortly after menarche, as is often found in cases of anorexia nervosa in adolescent girls (Crisp, 1970).

The absolute and relative increase in fatness from menarche to 16-18 years of age coincides with the period of adolescent subfecundity (Montague, 1979). During this time there is still rapid growth of the uterus, the ovaries, and the oviducts (Scammon, 1930).

Other factors, such as emotional stress, affect the maintenance or onset of menstrual cycles (Reichlin, 1982). Therefore, menstrual cycles may cease without weight loss and may not resume in some subjects even though the minimum weight for height has been achieved. Also, our standards apply as yet only to Caucasian United States females and European females, since different races have different critical weights at menarche and it is not yet known whether the different critical weights represent the same critical body composition of fatness (Frisch \& McArthur, 1974). 


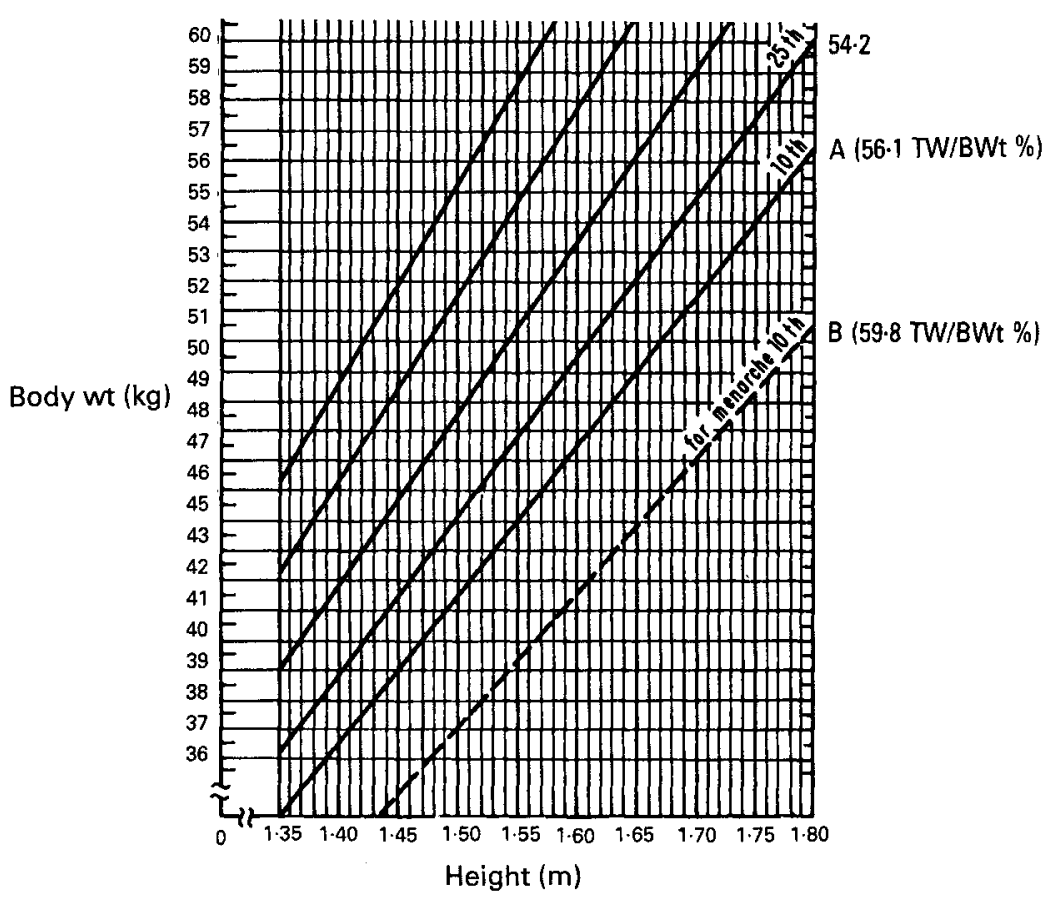

Fig. 2. The minimal weight necessary for a particular height for restoration of menstrual cycles is indicated on the weight scale by the 10th percentile diagonal line (A) of total water/body weight percent (TW/BWt \%), $56 \cdot 1$, as it crosses the vertical height line. For example, a 20-year-old woman whose height is $1.65 \mathrm{~m}(65 \mathrm{in})$ should weigh at least $49 \mathrm{~kg}(108 \mathrm{lb})$ before menstrual cycles would be expected to resume. The minimal weight necessary for a particular height for onset of menstrual cycles is indicated on the weight scale by the 10th percentile diagonal line (B) of TW/BWt \%, 59.8, as it crosses the vertical height lines. Height growth of girls must be completed, or approaching completion. For example, a 15-year-old girl whose completed height is $1.65 \mathrm{~m}(65 \mathrm{in})$ should weigh at least $43.6 \mathrm{~kg}$ (96 lb) before menstrual cycles can be expected to start. (Adapted from Frisch \& McArthur (1974) with permission from Science.)

Since the prediction of the minimum weights-for-height is from TW/BWt \% (not fat/body weight percent), I have suggested that the successful prediction is related to a lean mass:fat ratio, which is normally about 3:1 at menarche and 2.5:1 at the completion of growth at 18 years of age. As yet no prediction can be made above the threshold weight for a particular height.

\section{PHYSICAL EXERCISE, DELAYED MENARCHE AND AMENORRHOEA}

In the last decade it has become widely known that ballet dancers (Frisch et al. 1980b; Warren, 1980) and young prepubertal athletes have a delayed menarche. Frisch et al. $(1981 b)$ found that the mean age of menarche of thirty-eight college swimmers and runners was 13.9 (SE 0.3) years, significantly later $(P<0.001)$ than that of the general population, 12.8 (SE 0.05) years, in accord with other reports (Malina et al. 1978). However, the mean menarcheal age of the eighteen athletes whose training began before menarche was 15.1 (SE 0.5) years, whereas the mean menarcheal age of the twenty athletes whose training began after their menarche was 12.8 (SE 0.2$)$ years $(P<0.001)$. The latter mean age was similar to that of the college controls, 12.7 (SE 0.4 ) years, and 
the general population. Therefore, training, not preselection, is the delaying factor. Each year of premenarcheal training delayed menarche by 5 months $(0.4$ years). This suggests that one constructive way to reduce the incidence of teenage pregnancy would be to have girls join teams at ages $8-9$ years and maintain regular moderate exercise. Such a programme may reduce also the risk of the serious diseases of women in later life.

The training also directly affected the regularity of the menstrual cycles during the training year. Of the premenarche-trained athletes, only $17 \%$ had regular cycles, $61 \%$ were irregular and $22 \%$ were amenorrhoeic. In contrast, $60 \%$ of the postmenarchealtrained athletes were regular, $40 \%$ were irregular, and none were amenorrhoeic. However, during intense training the incidence of oligomenorrhoea and amenorrhoea increased in both groups.

As other workers have found (Dale et al. 1979; Schwartz et al. 1981) plasma gonadotrophins and oestrogen levels were in the low-to-normal range for the athletes with irregular cycles or amenorrhoea: Progesterone level was a follicular phase level. Thyroid hormones, however, were in the normal range (Frisch et al. 1981a). These athletes had increased muscularity and decreased adiposity, compared with non-athletes. The explanation of their menstrual disturbances, therefore, may be the same as for dieting, non-athletic women; too little fat in relation to the lean mass. Some of the swimmers and track and field athletes were above average weight-for-height. A raised lean:fat ratio may nevertheless have caused their menstrual problems, because their body weight represented a greater amount of muscle and less adipose tissue than the same weight of a non-athletic woman as was found by MRI (Gerard et al. 1991; Frisch et al. 1993).

\section{PSYCHOLOGICAL STRESS AND CHANGES IN WEIGHT}

The psychological stress of competition, which may increase the secretion of adrenal corticosteroids and catecholamines, thus affecting the hypothalamic control of gonadotrophins (Reichlin, 1982), may also be involved; but stress does not seem to be the main factor in many individuals. For example, a top-ranked $17 \cdot 5$-year-old swimmer who had a high score on a psychosocial test for tension had not had a menstrual period in 5 months. She was very lean; her height was $1.69 \mathrm{~m}$ (66.6 in) and her weight was $48.9 \mathrm{~kg}$ (108 lb), which is $82.5 \%$ of ideal weight and $2 \cdot 1 \mathrm{~kg}$ below the critical weight-for-height found necessary for regular cycles (Frisch \& MacArthur, 1974). After 2 months of training and no menses, this swimmer suddenly reported a $4 \mathrm{~d}$ period. On inquiry she reported she had gained $2.3 \mathrm{~kg}(5 \mathrm{lb})$ 'on purpose, by eating a lot of carbohydrate', to see if she would have a cycle. She lost the $2.3 \mathrm{~kg}(5 \mathrm{lb})$ by the next month and had no more cycles. What this small change in weight represents physiologically or endocrinologically is an intriguing question.

In contrast to the lean swimmer, a woman swimmer of the English Channel, who was studied during the training and postswim, had an ample supply of body fat (about $30 \%$ body weight) which preswim tests showed was necessary for maintenance of her body temperature. The reproductive changes during training included a shortened luteal phase, absence of ovulation and increased LH secretion relative to FSH. However, this swimmer did not become amenorrhoeic, even postswim, although the metabolic and hormonal data postswim, except cortisol, reflected the severe physiological stress; presumably there was also psychological stress (Frisch et al. 1984). 


\section{EVIDENCE FROM EXPERIMENTAL ANIMALS}

Rats fed on a high-fat diet, the fat being substituted isoenergetically for carbohydrate, had oestrus significantly earlier $(P<0 \cdot 001)$ than did rats fed on a low-fat diet (Frisch et al. 1975). We found also that the energy intake, on a per $\mathrm{kg}$ body weight basis, of the high-fat (HF) and low-fat (LF) diet rats did not differ at vaginal opening or at first oestrus, whereas the two groups differed significantly at both events in age, absolute food intake, relative food intake, and absolute energy intake.

Direct carcass analysis data showed that the rats fed on HF and LF diets had similar body compositions at oestrus, although the HF rats had oestrus at a lighter body weight than the LF rats (Frisch et al. 1977). The means for total water content (\% wet weight) were 66.2 (SE 0.3) for the HF rats and 66.4 (SE 0.3) for the LF rats, whereas the mean absolute total body water (g) for the two diet groups was $69 \cdot 7$ (SE 2.2) and 81.1 (SE 2.4) respectively $(P<0 \cdot 01)$.

\section{Food intake, ovulation and 'flushing'}

'Flushing' is the increase in the rate of twinning in sheep resulting from short-term (e.g. 1 week) high-energy feeding before mating to the ram (Coop, 1966). The well-nourished human female fortunately does not normally superovulate in response to a high energy intake, like a large steak dinner, although, interestingly, there is evidence for some residual flushing effect even in human subjects. The rate of human dizygotic twinning, but not monozygotic twinning, fell during wartime restrictions of nutrition in Holland and the rate returned to normal after the return of a normal food supply (Bulmer, 1970).

\section{MALE REPRODUCTION}

\section{Nutrition}

Undernutrition delays the onset of sexual maturation in boys (Tanner, 1962), similar to the delaying effect of undernutrition on menarche. Undernutrition and weight loss in men also affects their reproductive ability. The sequence of effects, however, is different from that of the female. In men loss of libido is an early effect of a decrease in energy intake and subsequent weight loss. Continued reduction of energy intake and weight loss results in a loss of prostate fluid, and decreases in sperm motility and sperm longevity, in that order. Sperm production ceases when weight loss is in the range of $25 \%$ of normal body weight. Refeeding results in a restoration of function in the reverse order of loss (Keys et al. $1950 a, b$ ).

\section{Effects of exercise on males}

Male marathon runners have recently been shown to have decreased hypothalamic GnRH secretion (MacConnie et al. 1986). Also reported are changes in serum testosterone levels with weight loss in wrestlers (Strauss et al. 1985); a reduction in serum testosterone and prolactin levels in male distance runners (Wheeler et al. 1984), and changes in reproductive function and development in relation to physical activity (Wall \& Cumming, 1985). 


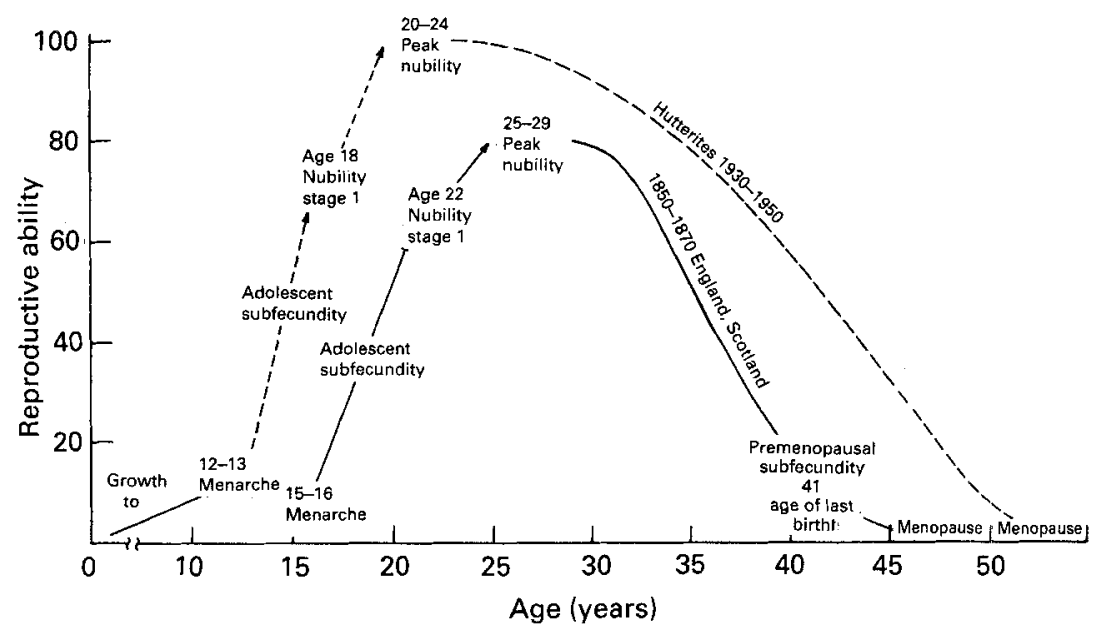

Fig. 3. The mid-19th-century curve for female reproductive ability (variation of the rate of childbearing with age) compared with that of the well-nourished modern Hutterites who do not practise contraception. The Hutterite fertility curve results in an average of ten to twelve children; the 1850-1870 fertility curve in about six to eight children. (Reprinted from Frisch (1978) with permission from Science).

\section{NUTRITION, PHYSICAL WORK AND NATURAL FERTILITY}

\section{Human reproduction reconsidered?}

The effects of hard physical work and nutrition on reproductive ability, discussed previously, suggested that differences in the fertility of populations, past and present, may be explained by a direct pathway from food intake to fertility (Frisch, 1975, 1978; Fig. 3), in addition to the classic Malthusian pathway through mortality. Charles Darwin $(1859,1894)$ described this commonsense direct relationship between food supplies and fertility, observing that: (1) domestic animals, which have regular, plentiful food without working to get it are more fertile than the corresponding wild animals, (2) 'hard living retards the period at which animals conceive', (3) the amount of food affects the fertility of the same individual, (4) it is difficult to fatten a cow which is lactating. All of Darwin's dicta apply to human beings (Frisch, 1978).

\section{The paradox of rapid population growth in undernourished populations}

In many historical populations with slow population growth, poor couples living together to the end of their reproductive lives had only six to seven living births. Most poor couples in many developing countries today also only have six to seven living births during their reproductive lifespan. This total fertility rate is far below the human maximum of eleven to twelve children observed among well-nourished societies not practising contraception, such as the Hutterites. But, six children per couple today in developing countries results in a very rapid rate of population growth because of decreased mortality rates, resulting from the necessary introduction of modern public health procedures. The difference between the birth rate/1000 and the death rate/1000 
(which gives the percentage growth rate) is now as high as 2,3 , and $4 \%$; populations growing at these rates double in 35,23 , and 18 years respectively.

British mid-19th-century data on growth rates, food intake, age-specific fertility, sterility, and ages of menarche and menopause show that females who grew relatively slowly to maturity, completing height growth at 20-21 years of age (instead of 16-18 years of age in well-nourished contemporary populations) also differed from wellnourished females in each event of the reproductive span: menarche is later, for example, $15 \cdot 0-16 \cdot 0$ years compared with $12 \cdot 8$ years; adolescent sterility is longer, the age of peak nubility is later; the levels of specific fertility are lower; pregnancy wastage is higher; the duration of lactational amenorrhoea is longer; the birth interval is, therefore, longer; and the age of menopause is earlier, preceded by a more rapid period of perimenopausal decline (Fig. 3; for additional references, see Frisch, 1978, 1983).

Thus, the slower, submaximal growth of women to maturity is subsequently associated with a shortened and less efficient reproductive span. The differences in the rate of physical growth of women and men result not only in a displacement of the age-specific fertility curve in time, but in a difference in the ultimate level; the faster the growth of the females and males, the earlier and more efficient the reproductive ability (Frisch, 1983).

Recent endocrinological findings show that undernourished women have a longer lactational amenorrhoea than do well-nourished women (Lunn et al. 1984; Fitzgerald, 1992). The amount of suckling is not the only factor, as has been suggested in explaining reduced natural fertility (Bongaarts, 1980). In addition, age of menarche and the other events of the reproductive span, which are known to be affected by the nutritional state, are pertinent to overall fertility (Frisch, 1983, 1984; Campbell \& Wood, 1988).

\section{Long-term, regular exercise lowers the risk of sex hormone-sensitive cancers}

The amenorrhoea and delayed menarche of athletes raised the question: are there differences in the long-term reproductive health of athletes with moderate training compared with non-athletes?

A study of 5398 college alumnae aged 20-80 years, 2622 of whom were former athletes, and 2776 were non-athletes, showed that the former athletes had significantly lower lifetime occurrence of breast cancer and cancers of the reproductive system than non-athletes. More than $82.4 \%$ of the former college athletes began their training in high school or earlier, compared with $24.9 \%$ of the non-athletes. The analysis controlled for potential confounding factors including age, age of menarche, age of first birth, smoking, cancer family history, etc. (Frisch et al. 1985). The relative risk (RR) for non-athletes/ athletes for cancers of the reproductive system was $2.53(95 \%$ confidence limits (CL) $1 \cdot 17,5 \cdot 47)$. The RR for breast cancer was $1.86(95 \% \mathrm{CL} 1 \cdot 00,3 \cdot 47)$. The former college athletes were leaner in every age-group compared with the non-athletes.

One can only speculate at present on the reasons for the lower risk; however, the most likely explanation is that over a long period of time the former athletes had lower levels of oestrogen because they were leaner, and more oestrogen was metabolized to the non-potent 2-hydroxyestrone oestrogen (Frisch et al. 1985; Hershcopf \& Bradlow, 1987). Obesity is a risk factor for breast cancer and cancer of the endometrium (Siiteri, 1981).

Also, the former athletes may have consumed diets lower in fat and saturated fat (Frisch et al. 1981a,b). Such diets shift the pattern of oestrogen metabolism toward the non-potent metabolite of oestradiol (Longcope et al. 1987). 
The former college athletes also had a lower lifetime occurrence (prevalence) of benign tumours of the breast and reproductive system (Wyshak et al. 1986), a lower prevalence of diabetes, particularly after 40 years of age, compared with the non-athletes (Frisch et al. 1986) and no greater risk of bone fractures, including risk of wrist and hip fractures, in the menopausal period, compared with non-athletes (Wyshak et al. 1987).

These findings indicate that long-term exercise, which was not Olympic or marathon level, but moderate and regular, reduces the risk of sex hormone-sensitive cancers, and the risk of diabetes for women, later in life. Recent findings showing moderate exercise also reduces the risk of non-reproductive system cancers (Blair et al. 1989; Frisch et al. 1989) suggest that other factors, such as changes in immunosurveillance, may also be involved.

\section{Magnetic resonance imaging of body fat of athletes and controls}

Using MRI we compared the subcutaneous and internal fat of seventeen athletes (thirteen oarswomen and four runners) and eleven non-athletic controls over a specific volume from the fifth thoracic vertebra (T5) to femoral fat (FF) in the upper thigh, and at four other anatomical sites. There were twenty-one to twenty-four axial scans per subject, the four other sites were at vertebrae lumbar one (L1), lumbar four (L4), sacral one (S1) and sacral four (S4) (Gerard et al. 1991). Frisch et al. (1993) found that: (1) the relative and absolute body fat of the athletes was significantly less $(P<0.05)$ than that of the controls, overall and at each of the six regional sites, although the mean body weight of the rowers was significantly higher than that of the controls, and the mean weight of the runners did not differ from that of the controls (Fig. 4). Thus, body weight and body mass index of a well-trained athlete can be a misleading indicator of body composition; (2) the subcutaneous fat:internal fat ratio of athletes and controls was the same $(80 \%$ body fat: $20 \%$ body fat), although compared with the controls, rowers had $27 \%$ less and athletes $40 \%$ less total body fat; (3) athletes with menstrual disorders had significantly decreased subcutaneous and internal fat, overall and at all regional sites, compared with controls. However, a subgroup of rowers who were ovulatory had more internal fat at three sites, level of vertebrae L4, S1 and S4, compared with controls, whereas their subcutaneous fat was lower at these sites than that of controls. This unexpected finding suggests that changes in regional fat deposits of both subcutaneous and internal fat may be involved in the menstrual dysfunction of some athletes, in addition to their decreased overall fatness; (4) the extent of oestradiol 2-hydroxylation to 2-hydroxy-oestrone $\left(2-\mathrm{OHE}_{1}\right)$ was significantly inversely related to total fat as a percentage of total volume $(P=0.005)$ and to subcutaneous fat as a percentage of total volume $(P=0.004)$ overall and at each of the regional fat depots (Frisch et al. 1993). This inverse relationship may be a determinant of the anovulatory cycles and amenorrhoea of excessively lean women, by a feedback to the hypothalamus, since 2-hydroxy-oestrone is anti-oestrogenic (Martucci \& Fishman, 1979).

The 2-hydroxylation of oestradiol is mediated by cytochrome P-450. The inverse relationship between MRI data on fatness and the 2-hydroxylation of oestradiol suggests that the higher risk of breast cancer and cancer of the endometrium (Siiteri, 1981) associated with fatness may be potentiated by a direct role of adipose tissue on cytochrome P-450 metabolism of oestradiol at the C-2 position (Bradlow et al. 1992). 
(A) Control

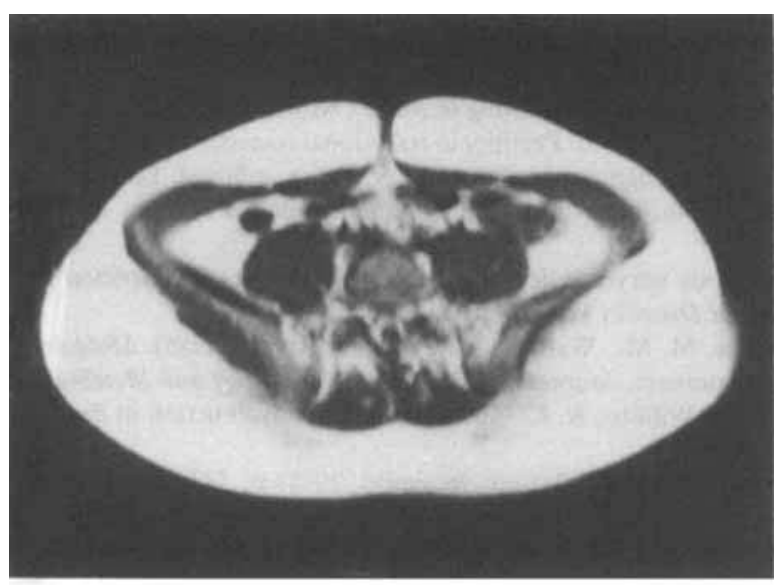

(B) Athlete

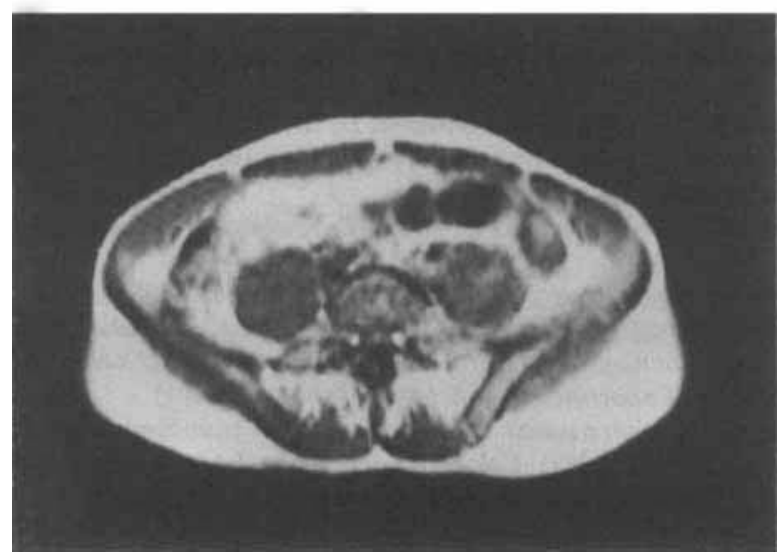

Fig. 4. Magnetic resonance imaging axial scans at the level of lumbar vertebra 4 (L4, level of umbilicus) of (A) a 20-year-old control and (B) a 22-year-old elite oarswoman during intensive training. Total fat/total volume \% at L4 of the control is 67.8, of the athlete 32.7. (Reprinted from Frisch et al. (1992), with permission from Metabolism.)

The preliminary research on the athletes and the Alumnae Health Study was supported by the Advanced Medical Research Foundation of Boston. The Magnetic Resonance Imaging Research was supported by Grant \#HD 23536 from the National Institute of Child Health and Development, National Institute of Health. The author thanks Jennifer Kennedy for the preparation of the manuscript.

\section{REFERENCES}

Apter, D., Bolton, N. J., Hammond, G. L. \& Vihko, R. (1984). Serum sex hormone-binding globulin during puberty in girls and in different types of adolescent menstrual cycles. Acta Endrocrinologica 107, 413-419.

Blair, S. N., Kohl, H. W. III, Paffenbarger, R. S., Clark, D. G., Cooper, K. H. \& Gibbons, L. W. (1989). Physical fitness and all-cause mortality. Journal of American Medical Association 262, 2395-2401.

Bongaarts, J. (1980). Does malnutrition affect fecundity? A summary of evidence. Science 208, 560-569.

Boyar, R. M., Katz, J., Finkelstein, J. W., Kapan, S., Weiner, H., Weitzman, E. D. \& Hellman, L. (1974). Anorexia nervosa: Immaturity of the 24-hour luteinizing hormone secretory pattern. New England Journal of Medicine 291, 861-865. 
Bradlow, H. L., Telang, N. T. \& Suto, A. (1992). Modulation of estrogen metabolism in estrogen responsive MCF-7 cell by adipocyte conditioned media. Proceedings of American Association of Cancer Research Program, Abstr. Naples, Florida.

Bulmer, M. G. (1970). The Biology of Twinning in Man. Oxford: Oxford University Press.

Campbell, K. L. \& Wood, J. W. (1988). Fertility in traditional societies. In Natural Human Fertility. Social and Biological Determinants [P. Diggory, M. Potts and S. Teper, editors]. London: Macmillan.

Coop, I. E. (1966). Effect of flushing on reproductive performance of ewes. Journal of Agricultural Science, Cambridge 67, 305-323.

Crisp, A. H. (1970). Anorexia nervosa: 'feeding disorder', 'nervous malnutrition', or 'weight phobia'? World Reviews of Nutrition and Dietetics 12, 452-504.

Cumming, D. C., Vickovic, M. M., Wall, S. R. \& Fluker, M. R. (1985). Defects in pulsatile LH release in normally menstruating runners. Journal of Clinical Endocrinology and Metabolism 6, 810-812.

Dale, D., Gerlach, D. H. \& Wilhite, A. L. (1979). Menstrual dysfunction in distance runners. Obstetrics and Gynecology 54, 47-53.

Darwin, C. (1859). Origin of Species, 1st ed. facsimile, 1975, p. 147. Cambridge, Massachusetts: Harvard University Press.

Darwin, C. (1894). The Variation of Animals and Plants Under Domestication, vol. 2, 2nd ed., pp. 88-99. New York: Appleton.

Eastman, N. J. \& Jackson, E. (1968). Weight relationships in pregnancy. I: The bearing of maternal weight gain and pre-pregnancy weight on birth weight in full term pregnancies. Obstetrics and Gynecology Survey 23, $1003-1025$.

Edelman, I. S., Haley, H. B., Scholerb, P. R., Sheldon, D. B., Friis-Hansen, B. J., Stoll, G. \& Moore, F. D. (1952). Further observations on total body water. I. Normal values throughout the life span. Surgery in Gynecology and Obstetrics 95, 1-12.

Emerson, K. Jr, Saxena, B. N. \& Poindexter, E. L. (1972). Caloric cost of normal pregnancy. Obstetrics and Gynecology 40, 786-794.

Feigelman, T., Frisch, R. E., MacBurney, M., Schiff, I. \& Wilmore, D. (1987). Sexual maturation in third and fourth decades, after nutritional rehabilitation by internal feeding. Journal of Pediatrics 111, 620-623.

Fishman, J., Boyar, R. M. \& Hellman, L. (1975). Influence of body weight on estradiol metabolism in young women. Journal of Clinical Endocrinology and Metabolism 41, 989-991.

Fitzgerald, M. H. (1992). Is lactation nature's contraceptive? Data from Samoa. Social Biology 39, 55-64.

Food and Agriculture Organization (1957). Calorie Requirements. FAO Bulletin. Rome: FAO

Friis-Hansen, B. J. (1956). Changes in body water compartments during growth. Acta Paediatrica, Suppl., 110, $1-67$.

Friis-Hansen, B. J. (1965). Hydrometry of growth and aging. In Human Body Composition. Symposia of the Society for the Sudy of Human Biology, vol. 7, pp. 191-209 [J. Brozek, editor]. Oxford: Pergamon.

Frisch, R. E. (1974). Critical weight at menarche, initiation of the adolescent growth spurt, and control of puberty. In Control of the Onset of Puberty, pp. 403-423 [M. Grumbach, D. Grave and F. E. Meyer, editors]. New York: John Wiley \& Sons.

Frisch, R. E. (1975). Demographic implications of the biological determinants of female fecundity. Social Biology 22, 17-22.

Frisch, R. E. (1976). Fatness of girls from menarche to age 18 years, with a nomogram. Human Biology $\mathbf{4 8}$, 353-359.

Frisch, R. E. (1977). Food intake, fatness and reproductive ability. In Anorexia Nervosa, pp. 146-161 [R. Vigersky, editor]. New York: Raven.

Frisch, R. E. (1978). Population, food intake and fertility. Science 199, 22-30.

Frisch, R. E. (1981). What's below the surface? New England Journal of Medicine 305, 1019-1020.

Frisch, R. E. (1983). Population, nutrition and fecundity. In Malthus Past and Present, pp. $393-404$ [J. Dupaquier, editor]. London: Academic Press.

Frisch, R. E. (1984). Body fat, puberty and fertility. Biological Reviews of the Cambridge Philosophical Society 59, 161-188.

Frisch, R. E. (1985). Fatness, menarche and female fertility. Perspectives in Biology and Medicine 28, 611-633.

Frisch, R. E. (1988). Fatness and fertility. Scientific American 258, 88-95.

Frisch, R. E., Canick, J. A. \& Tulchinsky, D. (1980a). Human fatty marrow aromatizes androgen to estrogen. Journal of Clinical Endocrinology and Metabolism 51, 394-396.

Frisch, R. E., Hall, G., Aoki, T. T., Birnholz, J., Jacob, R., Landsberg, L., Munro, H., Parkerjones, K., Tulchinsky, D. \& Young, J. (1984). Metabolic, endocrine and reproductive changes of a woman Channel swimmer. Metabolism 33, 1106-1111. 
Frisch, R. E., Hegsted, D. M. \& Yoshinaga, K. (1975). Body weight and food intake at early estrus of rats on high fat diet. Proceedings of the National Academy of Sciences, USA 72, 4172-4176.

Frisch, R. E., Hegsted, D. M., \& Yoshinaga, K. (1977). Carcass components at first estrus of rats on high fat and low fat diets: body water, protein, and fat. Proceedings of the National Academy of Sciences, USA 74, 379-383.

Frisch, R. E., \& McArthur, J. W. (1974). Menstrual cycles: fatness as a determinant of minimum weight for height necessary for their maintenance or onset. Science 185, 949-951.

Frisch, R. E. \& Revelle, R. (1971). Height and weight at menarche and a hypothesis of menarche. Archives of Diseases in Childhood 46, 695-701.

Frisch, R. E., Revelle, R. \& Cook, S. (1973). Components of weight at menarche and the initiation of the adolescent growth spurt in girls: Estimated total water, lean body weight and fat. Human Biology $\mathbf{4 5}$, 469-483.

Frisch, R. E., Snow, R. C., Gerard, E. L., Johnson, L., Kennedy, D., Barberi, R. \& Rosen, B. R. (1992). Magnetic resonance imaging of body fat of athletes compared to controls and the oxidative metabolism of estradiol. Metabolism 41, 191-193.

Frisch, R. E., Snow, R. C., Johnson, L. A., Gerard, B., Barberi, R. \& Rosen, B. (1993). Magnetic resonance imaging of overall and regional body fat, estrogen metabolism and ovulation of athletes compared to controls. Journal of Clinical Endocrinology and Metabolism 77, 471-477.

Frisch, R. E., Von Gotz-Welbergen, A., McArthur, J. W., Albright, T., Witschi, J., Bullen, B., Burnholz, J., Reed, R. B. \& Hermann, H. (1981a). Proceedings of Annual Meeting of Endocrine Society, Cincinnati, p. 119, Abstr. 147.

Frisch, R. E., Von Gotz-Welbergen, A., McArthur, J. W., Albright, T., Witschi, J., Bullen, B., Burnholz, J., Reed, R. B. \& Hermann, H. (1981b). Delayed menarche and amenorrhoea of college athletes in relation to age of onset of training. Journal of the American Medical Association 246, 1559-1563.

Frisch, R. E., Wyshak, G., Albright, N. L., Albright, T. E. \& Schiff, I. (1985). Lower prevalence of breast cancer and cancers of the reproductive system among former college athletes compared to non-athletes. British Journal of Cancer 52, 885-981.

Frisch, R. E., Wyshak, G., Albright, N. L., Albright, T. E. \& Schiff, I. (1989). Lower prevalence of non-reproductive system cancers among female former college athletes. Medicine and Science of Sports and Exercise 21, 250-253.

Frisch, R. E., Wyshak, G., Albright, T. E., Albright, N. L. \& Schiff, I. (1986). Lower prevalence of diabetes in female former college athletes compared with non-athletes. Diabetes 35, 1101-1105.

Frisch, R. E., Wyshak, G. \& Vincent, L. (1980b). Delayed menarche and amenorrhoea of ballet dancers. New England Journal of Medicine 303, 17-19.

Gerard, E. L., Snow, R. C., Kennedy, D. N., Frisch, R. E., Barberi, R., \& Rosen, B. R. (1991). MRI quantification of relative fatness and regional fat distribution in young women. American Journal of Roentgen 157, 99-104.

Green, B. B., Weiss, N. S. \& Daling, J. R. (1988). Risk of ovulatory infertility in relation to body weight. Fertility and Sterility 50, 721-725.

Hartz, A. J, , Barboriak, P. N., Wong, A., Katayama, K. P. \& Rimm, A. A. (1979). The association of obesity with infertility and related menstrual abnormalities in women. International Journal of Obesity 3, 57-73.

Hershcopf, R. J. \& Bradlow, H. L. (1987). Obesity, diet, endogenous estrogens, and the risk of hormonesensitive cancer. American Journal of Clinical Nutrition 45, 283-289.

Kaku, M. (1969). Disturbance of sexual function and adipose tissue of obese females. Sanfujinka No Jissai (Tokyo) 18, 212-218.

Kennedy, G. C. (1969). Interactions between feeding behavior and hormones during growth. Annals of New York Academy of Sciences 157, 1049-1061.

Kennedy, G. C. \& Mitra, J. (1963). Body weight and food intake as initiation factors for puberty in the rat. Journal of Physiology 166, 408-418.

Keys, A., Brozek, J., Henschel, A., Mickelson, O. \& Taylor, H. L. (1950a). The Biology of Human Starvation, vol. 1, pp. 753-763. Minneapolis: University of Minnesota Press.

Keys, A., Brozek, J., Henschel, A., Mickelson, O. \& Taylor, H. L. (1950b). The Biology of Human Starvation, vol. 2, pp. 839-840, 850-851. Minneapolis: University of Minnesota Press.

Longcope, C., Gorbach, S., Goldin, B., Woods, M., Dwyer, J., Morrill, A. \& Warram, J. (1987). The effect of a low fat diet on estrogen metabolism. Journal of Clinical Endocrinology and Metabolism 64, 1246-1250.

Lunn, P. G., Austin, S., Prentice, A. M. \& Whitehead, R. G. (1984). The effect of improved nutrition on plasma prolactin concentrations and postpartum infertility in lactating Gambian women. American Journal of Clinical Nutrition 39, 227-235. 
McArthur, J. W., O'Loughlin, K. M., Beitins, I. Z., Johnson, L., Hourihan, J. \& Alonso, C. (1976). Endocrine studies during the refeeding of young women with nutritional amenorrhoea and infertility. Mayo Clinic Proceedings 51, 607-615.

MacConnie, S. E., Barkan, A., Lampman, R. M., Schork, M. A. \& Beitins, I. Z. (1986). Decreased hypothalamic gonadotrophin-releasing hormone secretion in male marathon runners. New England Journal of Medicine 315, 411-417.

Malina, R. M., Spirduso, W. W., Tate, C. \& Baylor, A. M. (1978). Age at menarche and selected menstrual characteristics in athletes at different competitive levels and in different sports. Medicine and Science in Sports and Exercise 10, 218-222.

Marshall, F. H. A. \& Peel, W. R. (1908). 'Fatness' as a cause of sterility. Journal of Agricultural Science 3, 383-389.

Martucci, C. P. \& Fishman, J. (1979). Impact of continuously administered catechol estrogens on uterine growth and luteinizing hormone secretion. Endocrinology 105, 1288-1292.

Montague, A. (1979). The Reproductive Development of the Female: A Study in the Comparative Physiology of the Adolescent Organism. Littleton, Mass: PSG Publishing Co.

Moore, F. K., Olesen, H., McMurrey, J. D., Parker, V., Ball, M. R. \& Boyden, L. M. (1963). The Body Cell Mass and Its Supporting Environment. Philadelphia: W. B. Saunders Co.

Nillius, S. J. (1983). Weight and the menstural cycle. In Understanding Anorexia Nervosa and Bulimia. Report of the Fourth Ross Conference on Medical Research, pp. 77-81. Columbus, Ohio: Ross Laboratories.

Nimrod, A. \& Ryan, K. J. (1975). Aromatization of androgens by human abdominal and breast fat tissue. Journal of Clinical Endocrinology and Metabolism 40, 367-372.

Pasquali, R., Antenucci, D., Casimirri, F., Venturoli, S., Paradisi, R., Fabbri, R., Balestra, V., Melchionda, N. \& Barbara, L. (1989). Clinical and hormonal characteristics of obese amenorrhoeic hyperandrogenic women before and after weight loss. Journal of Clinical Endocrinology and Metabolism 68, 173-179.

Perel, E. \& Killinger, D. W. (1979). The interconversion and aromatization of androgens by human adipose tissue. Journal of Steroid Biochemistry 10, 623-626.

Prior, J. C. (1985). Luteal phase defects and anovulation: Adaptive alterations occurring with conditioning exercise. Seminars on Reproductive Endocrinology 3, 27-33.

Reichlin, S. (1982). Neuroendocrinology. In Textbook of Endocrinology, 6th ed., pp. 588-645. [R. H. Williams, editor]. Philadelphia: W. B. Saunders Co.

Scammon, R. E. (1930). The measurement of the body in childhood. In The Measurement of Man, [A. J. Harris, C. M. Jackson and D. G. Paterson, editors]. Minneapolis: University of Minnesota Press.

Schneider, J., Bradlow, H. L., Strain, G., Levin, J., Anderson, K. \& Fishman, J. (1983). Effects of obesity on estradiol metabolism: Decreased formation of nonuterotropic metabolites. Journal of Clinical Endocrinology and Metabolism 56, 973-978.

Schwartz, B., Cumming, D. C., Riordan, E., Selye, M., Yen, S. S. C. \& Rebar, R. W. (1981). Exercise-associated amenorrhoea: A distinct entity? American Journal of Obstetrics and Gynecology 141, 662-670.

Siteri, P. K. (1981). Extraglandular oestrogen formation and serum binding of estradiol: Relationship to cancer. Journal of Endocrinology 89, 119P-129P.

Siiteri, P. K. \& MacDonald, P. C. (1973). Role of extraglandular estrogen in human endocrinology. In Handbook of Physiology, section 7, vol. 2, part 1, pp. 615-629 [S. R. Geiger, E. B. Astwood and R. O. Greep, editors]. New York: American Physiology Society.

Snow, R. C., Barbieri, R. L. \& Frisch, R. E. (1989). Estrogen 2-hydroxylase oxidation and menstrual function among elite oarswomen. Journal of Clinical Endocrinology and Metabolism 69, 369-376.

Speroff, L., Glass, R. H. \& Kase, N. G. (1983). Clinical, Gynecologic Endocrinology and Infertility, 3rd ed., pp. 175-178. Baltimore: Williams and Wilkins.

Strauss, R. H., Lanese, R. R. \& Malarkey, W. B. (1985). Weight loss in amateur wrestlers and its effect on serum testosterone levels. Journal of American Medical Association 254, 3337-3338.

Tanner, J, W. (1962). Growth at Adolescence, 2nd ed. Oxford: Blackwell.

Van der Spuy, Z. M., Steer, P. J., Steele, S. J. \& Jacobs, H. S. (1988). Outcome of pregnancy in underweight women after spontaneous and induced ovulation. British Medical Journal 296, 962-965.

Van Wagenen, G. (1949). Accelerated growth with sexual precocity in female monkeys receiving testosterone propionate. Endocrinology 45, 544-546.

Vigersky, R. A., Andersen, A. E., Thompson, R. H. \& Loriaux, D. L. (1977). Hypothalarnic dysfunction in secondary amenorrhoea associated with simple weight loss. New England Journal of Medicine 297, $1141-1145$. 
Wall, S. R. \& Cumming, D. C. (1985). Effects on physical activity on reproductive function and development in males. Seminars in Reproductive Endocrinology 3, 65-80.

Warren, M. (1980). The effects of exercise on pubertal progression and reproductive function in girls. Journal of Clinical Endocrinology and Metabolism 51, 1050-1057.

Warren, M. P., Jewelewicz, R., Dyrenfurth, I., Ans, R., Khalaf, S. \& van de Weile, R. L. (1975). The significance of weight loss in the evaluation of pituitary response to LHRH in women with secondary amenorrhoea. Journal of Clinical Endocrinology and Metabolism 40, 601-611.

Wheeler, G. D., Wall, S. R., Belcastro, A. N. \& Cumming, D. C. (1984). Reduced serum testosterone and prolactin levels in male distance runners. Journal of American Medical Association 252, 514-516.

Wyshak, G. \& Frisch, R. E. (1982). Evidence for a secular trend in age of menarche. New England Journal of Medicine 306, 1033-1035.

Wyshak, G., Frisch, R. E., Albright, N. L. Albright, T. E. \& Schiff, I. (1986). Lower prevalence of benign diseases of the breast and benign tumors of the reproductive system among former college athletes compared to non-athletes. British Journal of Cancer 54, 841-845.

Wyshak, G., Frisch, R. E., Albright, T. E., Albright, N. L. \& Schiff, I. (1987). Bone fractures among former college athletes compared with non-athletes in the menopausal and postmenopausal years. Obstetrics and Gynecology 69, 121-126. 